\title{
Programmed intermittent epidural bolus for labour analgesia during first stage of labour: a sequential allocation trial to determine the effective interval time between boluses of a fixed volume of $2.5 \mathrm{~mL}$ of bupivacaine $0.25 \%$ plus fentanyl $8 \mu \mathrm{g} \cdot \mathrm{mL}^{-1}$ L'administration programmée de bolus périduraux pour l'analgésie du travail obstétrical pendant le premier stade du travail : une étude de répartition séquentielle pour déterminer le temps d'intervalle optimal entre des bolus d'un volume fixe de 2,5 $\mathrm{mL}$ de bupivacaïne $0,25 \%$ plus $8 \mu \mathrm{g} \cdot \mathrm{mL}^{-1}$ de fentanyl
}

Daniel Shatalin, MD (D) Cristian Arzola, MD, MSc • Kristi Downey, MSc •

Xiang Y. Ye, MSc • Jose C. A. Carvalho, MD, PhD

Received: 9 July 2020/Revised: 26 October 2020/Accepted: 27 October 2020/Published online: 2 February 2021

(c) Canadian Anesthesiologists' Society 2021

\begin{abstract}
Purpose We studied the programmed intermittent epidural bolus (PIEB) time interval between boluses of $2.5 \mathrm{~mL}$ of bupivacaine $0.25 \%$ with fentanyl $8 \mu \mathrm{g} \cdot \mathrm{mL}^{-1}$ to produce effective analgesia in $90 \%$ of women (EI90) during the first stage of labour.

Methods In a double-blind sequential allocation trial using a biased coin up-and-down design to determine the EI90, the PIEB boluses of $2.5 \mathrm{~mL}$ of $0.25 \%$ bupivacaine plus fentanyl $8 \mu \mathrm{g} \cdot \mathrm{mL}^{-1}$ were delivered at varying intervals-60, 50, 40, and $30 \mathrm{~min}$. The primary outcome was the adequate response of the patient to the PIEB regimen, defined as no use of supplemental analgesia for six hours or until the first stage of labour was completed, whichever came first. The secondary outcomes were the upper sensory block level to ice, motor block and hypotension. The isotonic regression with extrapolation approach was used to estimate the EI9O.
\end{abstract}

D. Shatalin, MD $(\varangle) \cdot$ C. Arzola, MD, MSc

K. Downey, MSc · J. C. A. Carvalho, MD, PhD

Department of Anesthesia and Pain Management, Mount Sinai Hospital, University of Toronto, 600 University Avenue, Room 7-405, Toronto, ON M5G 1X5, Canada

e-mail: danielsmail@gmail.com

X. Y. Ye, MSc

Department of Pediatrics, Micare Research Centre, Mount Sinai Hospital, University of Toronto, Toronto, ON, Canada
Results In the 20 women studied, the estimated EI90 was 20 (95\% CI, 5.9 to 28.8) $\mathrm{min}$. For the secondary outcomes, we classified women into those assigned to $30 \mathrm{~min}(16$ women) and those assigned to more than 30 min (four women). The median upper sensory block for women in the 30-min group and more than 30 min were T6 (or T5) and T7, respectively. No participants experienced motor block. Hypotension occurred in one patient in the 30-min group. Conclusion The estimated EI90 for boluses of $2.5 \mathrm{~mL}$ of bupivacaine $0.25 \%$ with fentanyl $8 \mu \mathrm{g} \cdot \mathrm{mL}^{-1}$ was $20195 \%$ CI, 5.9 to 28.8) min. These results suggest that there is no advantage in using this regimen compared with those reported in the literature using the same dose of bupivacaine in concentrations of $0.0625 \%$ and $0.125 \%$.

Trial registration $w w w$.clinicaltrials.gov (NCT03735771); registered 7 November 2018.

Résumé

Objectif Nous avons étudié l'intervalle de temps d'administration programmée de bolus périduraux (PIEB) entre des bolus de 2,5 mL de bupivacaine 0,25\% avec $8 \mu \mathrm{g} \cdot \mathrm{mL}^{-1}$ de fentanyl nécessaire pour procurer une analgésie efficace chez $90 \%$ des femmes (IE90) au cours du premier stade du travail obstétrical.

Méthode Dans une étude de répartition séquentielle à double insu utilisant une méthodologie de tirage au sort biaisé de haut en bas pour déterminer l'IE90, des bolus 
PIEB de $2,5 \mathrm{~mL}$ de bupivacaine $0,25 \%$ plus $8 \mu \mathrm{g} \cdot \mathrm{mL}^{-1}$ fentanyl ont été administrés à des intervalles variables 60, 50, 40 et 30 min. Le critère d'évaluation principal était une réponse adéquate de la patiente au régime de PIEB, définie comme aucun recours à une analgésie supplémentaire pendant six heures ou jusqu'à la fin du premier stade du travail, à la première condition obtenue. Les critères d'évaluation secondaires comportaient le niveau du bloc sensitif supérieur tel qu'établi par un test de glace, ainsi que la présence d'un bloc moteur et d'hypotension. Nous avons utilisé une méthode de régression isotonique avec une approche d'extrapolation pour estimer l'IE90.

Résultats Chez les 20 femmes étudiées, l'IE90 estimé était de 20 (IC 95 \%, 5,9 à 28,8) min. En ce qui touche aux critères d'évaluation secondaires, nous avons catégorisé les femmes selon qu'elles étaient assignées à recevoir un bolus aux 30 min (16 femmes) ou à des intervalles de plus de $30 \mathrm{~min}$ (quatre femmes). Le niveau du bloc sensitif supérieur médian pour les femmes dans le groupe 30 min et plus de 30 min se situait à T6 (ou T5) et T7, respectivement. Aucune participante n'a subi de bloc moteur. Une patiente dans le groupe à 30 min a subi un épisode d'hypotension. Conclusion L'IE90 estimé pour les bolus de 2,5 $\mathrm{mL}$ de bupivacaïne $0,25 \%$ avec $8 \mu \mathrm{g} \cdot \mathrm{mL}^{-1}$ de fentanyl était de 20 (IC $95 \%, 5,9$ à 28,8) min. Ces résultats suggèrent qu'il n'y a aucun avantage à utiliser ce régime posologique plutôt que ceux rapportés dans la littérature utilisant une même dose de bupivacaïne à des concentrations de 0,0625\% et $0,125 \%$.

Enregistrement de l'étude www.clinicaltrials.gov (NCT 03735771); enregistrée le 7 novembre 2018.

Keywords Labor analgesia - Epidural .

Programmed intermittent epidural boluses

Programmed intermittent epidural bolus (PIEB) is an epidural analgesia "maintenance" technique in which boluses of local anesthetic solutions are injected into the epidural space at a fixed time interval. Studies comparing PIEB to continuous epidural infusions (CEI) have shown that PIEB is associated with reduced local anesthetic consumption, ${ }^{1}-{ }^{6}$ longer duration of analgesia, ${ }^{4,7}$ lower incidence of breakthrough pain, ${ }^{8}$ and greater maternal satisfaction. ${ }^{1,4,8}$ There is evidence that PIEB regimens decrease motor block and instrumental deliveries. ${ }^{9,10}$ Despite the increasingly popular use of PIEB for labour analgesia, the optimum regimen of drug delivery including drug type, concentration, bolus interval, and dose using PIEB has yet to be determined. ${ }^{11}$
Our group has conducted three studies ${ }^{12}{ }^{14}$ with different bupivacaine concentrations, volumes, and boluses intervals, aiming at establishing the optimum PIEB regimen for women during the first stage of labour. In those studies, we found that more than $40 \%$ of the women experienced sensory blocks to ice above the T6 dermatome level. While these sensory block levels were not associated with significant adverse effects in those studies, they are not required for labour analgesia and may potentially determine adverse effects.

Our first study $^{12}$ was a prospective, double-blind, sequential allocation study to determine the effective interval of PIEB in 90\% of women (EI90) during first stage of labour, while using a fixed bolus of $10 \mathrm{~mL}$ of bupivacaine $0.0625 \%$ with fentanyl $2 \mu \mathrm{g} \cdot \mathrm{mL}^{-1}$. Our results showed that the PIEB time interval to provide effective analgesia (defined as no need for patient-controlled epidural analgesia [PCEA] or manual boluses for six hours after the loading dose or until the patient completed the first stage of labour, whichever occurred first) was approximately $40 \mathrm{~min}$, which corresponds to an hourly consumption of $9.4 \mathrm{mg}$ of bupivacaine.

We subsequently conducted a second study ${ }^{13}$ with the same anesthetic solution and the same PIEB interval of 40 min, aiming to determine the effective volume (dose) of local anesthetic while producing the same outcome of effective analgesia without breakthrough pain. We concluded that the volume (dose) could not be reduced without compromising the efficacy of the technique. These results validated those of our previous study.

We finally conducted a third study ${ }^{14}$ to determine the effective time interval between boluses of a more concentrated solution, bupivacaine $0.125 \% 5 \mathrm{~mL}$ plus fentanyl $2 \mu \mathrm{g} \cdot \mathrm{mL}^{-1}$, while maintaining the same dose of local anesthetic. We observed that the EI90 for boluses of 5 $\mathrm{mL}$ of bupivacaine $0.125 \%$ with fentanyl $2 \mu \mathrm{g} \cdot \mathrm{mL}^{-1}$ was approximately $35 \mathrm{~min}$. Surprisingly, similar to what we had observed in our two previous studies, the incidence of women exhibiting sensory block to ice $>\mathrm{T} 6$ was still high, approximately $58.4 \%$.

Based on these three previous studies, we sought to test even smaller volumes of more concentrated solutions. We therefore planned the current study using boluses of $2.5 \mathrm{~mL}$ of bupivacaine $0.25 \%$ with fentanyl $8 \mu \mathrm{g} \cdot \mathrm{mL}^{-1}$, which maintained the same dose of bupivacaine and fentanyl per bolus used in our previous studies, but in a much smaller volume. We believed that a reduced bolus volume would lead to a more limited spread of the epidural mixture, which in turn could lead to better usage of the local anesthetic by reducing its hourly consumption without compromising the technique.

The objective of this study was to establish the effective PIEB interval between boluses of bupivacaine $0.25 \%$ plus 
fentanyl $8 \mu \mathrm{g} \cdot \mathrm{mL}^{-1}$ that would be effective in $90 \%$ of nulliparous women requesting epidural analgesia during the first stage of labour, without breakthrough pain and no need for PCEA or physician/nurse administered bolus. Our hypothesis was that the effective interval time between PIEB boluses of $2.5 \mathrm{~mL}$ of $0.25 \%$ bupivacaine plus fentanyl $8 \mu \mathrm{g} \cdot \mathrm{mL}^{-1}$ would be between 30 and $60 \mathrm{~min}$.

\section{Methods}

We conducted a double-blind sequential allocation trial using a biased coin up-and-down design to determine the effective PIEB interval in 90\% (EI90) of our studied population.

The study was approved by the Research Ethics Board at Mount Sinai Hospital in Toronto, Canada (REB 18-0219A, approval date 8 November 2018) and written informed consent was obtained from all participants. The study was registered at ClinicalTrials.gov on 7 November 2018 (identifier: NCT03735771).

We recruited American Society of Anesthesiologists physical status II or III nulliparous women at a gestational age $\geq 37$ weeks, with singleton fetuses in vertex presentation. We studied women in active labour (regular contractions occurring three to five minutes apart and cervical dilatation between 2 and $5 \mathrm{~cm}$ ), requesting labour epidural analgesia during the first stage of labour (induced or augmented), with verbal numerical pain score (VNPS) greater than five at the time of epidural analgesia request (VNPS 0-10). Exclusion criteria included refusal to participate in the trial, any contraindication to epidural anesthesia, allergy or hypersensitivity to bupivacaine or fentanyl, and the use of other analgesics within the last four hours. Withdrawal criteria included unintentional dural puncture during epidural placement, and unsatisfactory response to the loading dose (defined as verbal numerical rating scale [VNRS] $>1$ at $20 \mathrm{~min}$ after the epidural loading dose).

An infusion of $250 \mathrm{~mL}$ of lactated Ringer's solution was given to the patient during epidural catheter placement. The epidural catheter was placed in the sitting position, with a midline approach, and the epidural puncture site was determined by pre-procedure spinal ultrasound assessment. After skin preparation with chlorhexidine $2 \%$ and alcohol $70 \%$, skin was infiltrated with lidocaine $2 \%$. A $17 \mathrm{G}$ Tuohy needle was inserted at the L3/4 interspace using loss of resistance to air or saline at the discretion of the anesthesiologist. A closed-end, multi-orifice, wirereinforced epidural catheter (Arrow FlexTip plus; Arrow International Inc, Reading, PA, USA) was advanced 4-5 $\mathrm{cm}$ into the epidural space and was then aspirated and secured. Patients were positioned supine with left uterine displacement and $30^{\circ}$ head-of-bed elevation.

A test dose of $3 \mathrm{~mL}$ of bupivacaine $0.125 \%+$ fentanyl $3.3 \mu \mathrm{g} \cdot \mathrm{mL}^{-1}$ was given. After assessment of the test dose at three minutes, a loading dose of $12 \mathrm{~mL}$ of $0.125 \%$ bupivacaine with fentanyl $3.3 \mu \mathrm{g} \cdot \mathrm{mL}^{-1}$ was administered in two aliquots of $6 \mathrm{~mL}$. Patient monitoring followed institutional practice. Hypotension, defined as a decrease in blood pressure of $20 \%$ from baseline values in combination with symptoms (nausea, dizziness, vomiting or fetal bradycardia), was treated by a $250-\mathrm{mL}$ rapid fluid infusion of lactated Ringer's and/or $5 \mathrm{mg}$ of intravenous ephedrine at the discretion of the anesthesiologist.

The efficacy of the epidural loading dose was assessed at 20 min after the end of the full loading dose, as per our standard practice. A successful response to the loading dose was defined as a VNRS $\leq 1$ on a $0-10$ scale. If no satisfactory response was obtained at $20 \mathrm{~min}$, the epidural loading dose was considered to have failed for study purposes and the patient was withdrawn from the study and managed as per clinician preferences.

Those patients responding successfully to the loading dose had their PIEB regimen initiated at $60 \mathrm{~min}$ post loading dose. The PIEB regimen was administered with a CADD ${ }^{\circledR}$-Solis Ambulatory Infusion System (Smith Medical, St Paul, MN, USA). The pump was programmed to deliver boluses at $250 \mathrm{~mL} \cdot \mathrm{hr}^{-1}$ as per our routine.

The biased coin up-and-down sequential allocation was carried out using a computer-generated list of random responses prepared by the biostatistician using Excel (Microsoft, Redmond, WA, USA). A research assistant used this list to provide the PIEB setting for the next woman in a sealed envelope. An unblinded research assistant or consultant anesthesiologist set up the epidural infusion pump. The screen of the epidural infusion pump was covered with paper to blind the participants, other investigators, and nurses.

The PIEB pump delivered boluses of $2.5 \mathrm{~mL}$ of $0.25 \%$ bupivacaine plus fentanyl $8 \mu \mathrm{g} \cdot \mathrm{mL}^{-1}$ at different intervals. The PIEB interval was determined by a biased coin up-anddown sequential allocation design targeting for the effective interval that provided EI90 defined as no need for PCEA or manual boluses for 6 hours after the loading dose or until the patient completed the first stage of labour (fully dilated), whichever occurred first. The maximum interval was $60 \mathrm{~min}$ and the minimum interval was $30 \mathrm{~min}$, therefore delivering a total volume of the epidural mixture varying from $2.5 \mathrm{~mL}$ (group $60 \mathrm{~min}$ ) to $5 \mathrm{~mL}$ (group 30 min) per hour, which corresponds to a dose of $6.25-12.5$ $\mathrm{mg}$ of bupivacaine per hour, respectively.

The PIEB intervals that were investigated were 60,50 , 40 , and $30 \mathrm{~min}$. If a patient did not respond adequately to 
the current PIEB interval, the case was considered to have failed for study purposes and the patient was switched to the standard PIEB regimen in practice at Mount Sinai Hospital. In that case, the PIEB interval for the subsequent study patient was decreased by ten minutes. If the patient responded to the PIEB interval, the case was considered a success, and the PIEB interval for the subsequent patient was increased by ten minutes with a probability of $1 / 9$, otherwise it remained unchanged. In case of a successful response in group 60 or a failure in group 30, the interval for the subsequent patients was kept the same until the biased coin program indicated a decrease or increase in the interval, respectively.

The upper sensory block to ice was assessed bilaterally at the mid-clavicular lines, and the level of block was one level below that where the patient felt as cold as the forehead or cheek. Motor block was assessed according to the modified Bromage score ${ }^{15}(0=$ able to raise extended legs; 1 = unable to raise extended legs but able to flex knees; 2 = unable to flex knees but able to flex ankle; $3=$ unable to flex ankle). Pain score was assessed according to a VNRS 0-10, where: $0=$ no pain and $10=$ worst imaginable pain. Non-invasive blood pressure was assessed at 20 and $60 \mathrm{~min}$ after completing the loading dose, and then every $60 \mathrm{~min}$ until the end of the study.

If the PIEB interval proved insufficient during the study period, the next vaginal examination and cervix dilation was noted to ensure the patient had requested supplemental analgesia still during the first stage of labour.

The primary outcome of the study was the adequate response of the patient to the PIEB regimen, defined as no request for supplemental analgesia (PCEA bolus or clinician administered bolus) until completion of first stage of labour or until six hours following initiation of PIEB, whichever occurred first.

The secondary outcomes were the upper sensory block level to ice, motor block according to Bromage score, pain scores, hypotension, and treatment of hypotension (type of intervention).

Additional recorded data included age, weight, height, gravidity, parity, gestational age, cervical dilation, status of membranes, type of labour (spontaneous or induced), oxytocin use, consumption of bupivacaine (total amount, hourly consumption).

\section{Statistical analysis}

For a dose finding study based on biased coin up-and-down design, the distribution of data are unknown and nonindependent. This prevents the development of theoretical rules to estimate the sample size for a pre-specified precision of the EI90 estimation. Simulation studies suggest that enrolling at least $20-40$ patients will provide stable estimates of the target volume for most realistic cases. ${ }^{16}$ In this study, we enrolled 20 patients.

Descriptive statistical methods were used to summarize the study population. Because all the observed responses rates fell below $90 \%$, which implied that the EI90 was not in the interval range investigated (60, 50, 40, and $30 \mathrm{~min}$ ), the planned Dixon and Mood method and isotonic regression method (with interpolation approach) ${ }^{16}$ for estimating EI90 were not applicable. Instead, we applied the isotonic regression with extrapolation approach ${ }^{17,18}$ to estimate the EI90. To be specific, assuming $\Omega=\{x(1)<x(2)<\ldots<x(k)\} \quad$ be the $\mathrm{k}$ intervals investigated and $p(i)$ be the observed rate of the primary outcome of success at interval $x(i), i=1,2,3, \ldots, k$. Since the observed rate of $p=\{p(1), p(2), \ldots, p(k)\}$ may not be decreased with respect to the interval (min), the implicit assumption of the study, the isotonic regression with the PAVA algorithm ${ }^{16}$ was first used to obtain a decrease adjusted rate $p^{*}=\left\{p^{*}(1) \geq p^{*}(2) \geq, \ldots, \geq p^{*}(k)\right\}$ based on $p$. Similar to the isotonic regression estimator with linear interpolation approach, ${ }^{19}$ the isotonic regression estimator of EI90 with the linear extrapolation approach here was the interval $\hat{U}=\frac{0.9-p^{*}(1)}{p^{*}(1)-p^{*}(2)}(x(1)-x(2))+x(1)$, since $x(1)=\min \left(x(i): p^{*}(i)<0.9\right)$ when all $p^{*}(i)<0.9$. The $95 \%$ confidence interval (CI) of the EI90 was obtained by a bias-corrected percentile method $^{16}$ using 2000 bootstrap replications of $\hat{U}^{*}$. Each replication was obtained by drawing a bootstrap data set with a sample size of 20 and BCUD design, assuming the true doseresponse rate at each interval $(\min )$ is $p^{*}(i), i=1,2,3$, $\ldots, k$ estimated based on the original data, and then estimated $\hat{U}^{*}$, the isotonic regression estimator of ED90 with linear extrapolation approach based on the bootstrap data.

Patient characteristics and secondary outcomes were described/compared between two groups, those with PIEB interval of $30 \mathrm{~min}$ and those with PIEB more than $30 \mathrm{~min}$. All the de-identified data were analyzed by the study biostatistician.

\section{Results}

Forty-eight women were approached to participate in the study from November 2018 to June 2019. Of these, 17 declined to participate, nine were not eligible, and two were excluded because of a failed loading dose (pain prior to PIEB regimen starting). Therefore, 20 women were included in the data analysis. Patient demographics and obstetric characteristics are shown in Table 1.

The patient allocation sequence and response to different PIEB interval times is shown in the Figure. The 
response rate for each time interval and the adjusted response rates are shown in Table 2.

From the data observed, the EI90 likely falls below 30 min, and could not be calculated using the planned methods, the Dixon and Mood method and the traditional isotonic regression with interpolation approach method. We instead used the isotonic regression with extrapolation approach to estimate the EI90 and the bootstrap method for the $95 \%$ CI. The estimated EI90 was 20 (95\% CI, 5.9 to 28.8) $\min$.

Table 3 depicts the highest upper sensory level and degree of motor block for the duration of the study. Given the small number of women assigned PIEB intervals longer than $30 \mathrm{~min}$, we combined the participants in two groups only, those assigned to $30 \mathrm{~min}$ and those assigned to more than $30 \mathrm{~min}$. The median upper sensory block level for

Table 1 Patient characteristics and obstetric data

\begin{tabular}{ll}
\hline Characteristics & $N=20$ \\
\hline Age (yr), mean (SD) & $32.7(5.9)$ \\
Weight $(\mathrm{kg})$, mean (SD) & $78.8(12.2)$ \\
Height $(\mathrm{cm})$, mean (SD) & $165(6)$ \\
BMI $\left(\mathrm{kg} \cdot \mathrm{m}^{-2}\right)$, mean (SD) & $29.1(5.6)$ \\
Gestational age (weeks), mean (SD) & $39.3(0.9)$ \\
Nulliparous, $n(\%)$ & $20(100)$ \\
Membranes ruptured, $n(\%)$ & $14(70)$ \\
VASpain before epidural, median [IQR] & $8[7-9]$ \\
Baseline SBP, mean (SD) & $120(8.4)$ \\
Cervical dilation at epidural request, median [IQR] & $3[2-4]$ \\
Cervical dilation nearest to study completion, & $5[4-7]$ \\
median [IQR] & \\
Labour, $n$ (\%) & \\
Spontaneous labour & $14(70)$ \\
Induced labour & $6(30)$ \\
Oxytocin administration, $n(\%)$ & $9(45)$ \\
\hline
\end{tabular}

$\mathrm{BMI}=$ body mass index; $\mathrm{IQR}=$ interquartile range; $\mathrm{SBP}=$ systolic blood pressure; $\mathrm{SD}=$ standard deviation; $\mathrm{VAS}=$ visual analogue scale.

Table 2 Observed and PAVA-adjusted response rate

\begin{tabular}{lllll}
\hline $\begin{array}{l}\text { Assigned } \\
\text { dose }\end{array}$ & $\begin{array}{l}\# \\
\text { success }\end{array}$ & $\begin{array}{l}\# \\
\text { patient }\end{array}$ & $\begin{array}{l}\text { Observed } \\
\text { response rate }(\%)\end{array}$ & $\begin{array}{l}\text { PAVA-adjusted } \\
\text { response rate }(\%)\end{array}$ \\
\hline 60 & 0 & 1 & 0 & 0 \\
50 & 0 & 1 & 0 & 0 \\
40 & 1 & 2 & 50 & 50 \\
30 & 11 & 16 & 69 & 69 \\
\hline
\end{tabular}

PAVA-adjusted response rates were estimated using weighted isotonic regression method. PAVA $=$ pool-adjacent-violators algorithm. women in the 30-min group and those assigned to more than 30 min were T6 (or T5) and T7, respectively. No participants experienced motor block. Asymptomatic hypotension that required pharmacologic treatment occurred in just one patient in the 30-min group.

\section{Discussion}

Our results show that the estimated EI90 for our studied PIEB regimen using boluses of $2.5 \mathrm{~mL}$ of bupivacaine $0.25 \%$ with fentanyl $8 \mu \mathrm{g} \cdot \mathrm{mL}^{-1}$ is $20 \mathrm{~min}$. This interval is outside the interval considered in our hypothesis, which was between 30 and $60 \mathrm{~min}$. This is different from our three previous studies, ${ }^{12}{ }^{14}$ where the optimal interval was always above $30 \mathrm{~min}$. Our results suggest that, contrary to our assumption, the consumption of local anesthetic with this regimen is higher than in our previous studies, and that there is no advantage in using boluses of $2.5 \mathrm{~mL}$ of bupivacaine $0.25 \%$ plus fentanyl $8 \mu \mathrm{g} \cdot \mathrm{mL}^{-1}$.

The optimal PIEB regimen for epidural analgesia has yet to be determined. ${ }^{11}$ Obstetric anesthesia units adopting the PIEB technique will likely have to adapt different regimens already proposed in the literature, or develop their own, to suit the needs and expectations of their patient population. $^{20}$

The spread of solutions into the epidural space is complex and multifactorial, and to date, not completely understood. Two previous studies conducted by our group $^{13,14}$ used the same dose of local anesthetic in different concentrations and showed very similar results, including effective PIEB time intervals, motor block, and extent of sensory block, with a high proportion of women exhibiting a sensory block to ice above the T6 dermatome. These findings led us to look for further optimization of our PIEB regimen, given that such a wide spread of sensory analgesia is neither necessary nor desired.

Our hypothesis that a more concentrated solution and smaller volume could lead to more effective use of local anesthetic was actually in conflict with the existing evidence that more dilute solutions are in fact more effective. Nevertheless, most data available on that topic relate to CEI techniques and we wanted to test this hypothesis in the context of the PIEB technique. Previous data based on the use of CEI method ${ }^{21,22}$ speak in favour of the use of diluted local anesthetic solutions. Ginosar et al. ${ }^{21}$ compared a group of women receiving a $5 \mathrm{~mL}$ bolus and 5 $\mathrm{mL} \cdot \mathrm{hr}^{-1}$ infusion of bupivacaine $0.25 \%$ with a group of women receiving a bolus of $20 \mathrm{~mL}$ and $20 \mathrm{~mL} \cdot \mathrm{hr}^{-1}$ of diluted bupivacaine $(0.0625 \%)$. The authors concluded that women who received diluted local anesthetic solutions required less supplemental analgesia, had greater maternal satisfaction, and less local anesthetic consumption. 
Table 3 Upper sensory block level to ice and motor block

\begin{tabular}{|c|c|c|c|}
\hline & \multicolumn{2}{|c|}{ PIEB time interval group } & \multirow{2}{*}{$\begin{array}{l}\text { All } \\
n=20\end{array}$} \\
\hline & $\begin{array}{l}>30(\min ) \\
(n=4)\end{array}$ & $\begin{array}{l}30(\min ) \\
(n=16)\end{array}$ & \\
\hline Highest sensory level L to ice, median [IQR] & $\mathrm{T} 7$ [T7-T7] & T6 [T5-T6] & T6 [T5/T6-T7] \\
\hline Highest sensory level $\mathrm{R}$ to ice, median [IQR] & $\mathrm{T} 7$ [T7-T7] & T5/T6 [T5-T6] & T6 [T5-T7] \\
\hline Highest degree of motor block L, median [IQR] & $0[0-0]$ & $0[0-0]$ & $0[0-0]$ \\
\hline Highest degree of motor block R, median [IQR] & $0[0-0]$ & $0[0-0]$ & $0(0,0)$ \\
\hline
\end{tabular}

$\mathrm{IQR}$ = interquartile range; $\mathrm{L}=$ left; PIEB = programmed intermittent epidural bolus; $\mathrm{R}$ = right; motor block (Bromage score 0-3).

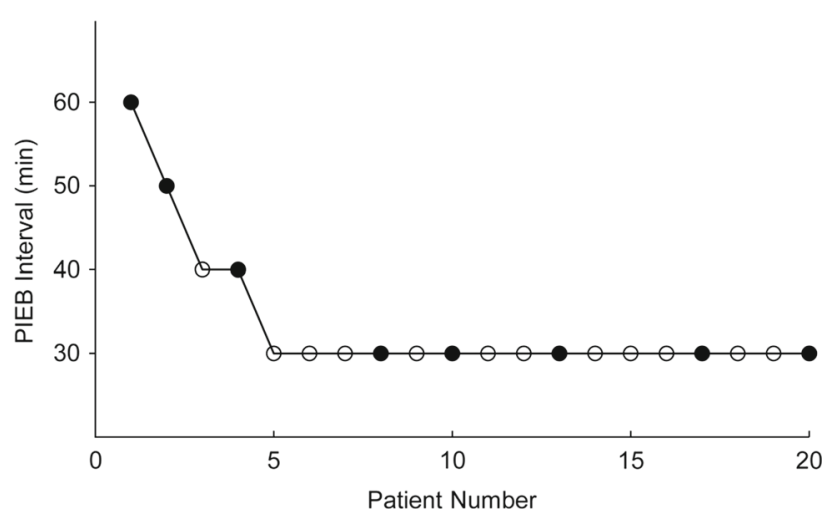

Solid circle $=$ inadequate PIEB time interval, open circle $=$ adequate PIEB time interval

PIEB $=$ programmed intermittent epidural bolus

Figure Individual responses of study participants to different PIEB time intervals. Solid circle $=$ inadequate PIEB time interval, open circle $=$ adequate PIEB time interval

Nevertheless, as already highlighted, it is important to note that these studies ${ }^{21,22}$ evaluated a CEI with PCEA method and not a PIEB method where the physiologic concept is very different. The physiologic advantage of PIEB, as shown by the Kaynar and Shankar ${ }^{23}$ and Hogan ${ }^{24}$ studies, may be explained by the higher pressure and consequently better distribution of medication and greater longitudinal extent of circumferential spread in the epidural space. In another recent study, increased spread of epidural contrast was shown in pigs with the PIEB technique compared with CEI. $^{25}$

Overall, our study suggests that the consumption of local anesthetic may in fact increase with the use of more concentrated solutions. To achieve optimal labour analgesia with the more concentrated solution (i.e., $0.25 \%$ bupivacaine), our study showed that the PIEB bolus interval time of $30 \mathrm{~min}$ is insufficient nearly one third of the time and a lower interval would be needed. Furthermore, using the extrapolated PIEB bolus interval of $20 \mathrm{~min}$ would increase the total hourly bupivacaine consumption dose to $18.75 \mathrm{mg}$, almost twice the dose of previously reported studies with less concentrated bupivacaine. $^{12}{ }^{14}$

Our results are therefore in keeping with the studies using CEI and PCEA regimens, where better results were obtained with more diluted solutions. It is important to note that our study is not a comparative one. Nevertheless, the estimated EI90 of $20 \mathrm{~min}$ (95\% CI, 5.9 to 28.8) suggests that there would be no advantage in using concentrated solutions because of increased consumption of local anesthetic.

An interesting finding in our study that is no participant experienced motor block. This could be just a random finding. Given that we in fact increased the hourly administration of local anesthetic compared with what we used in our previous studies, it would not be surprising if a patient presented with some degree of motor block. Nevertheless, as previously observed in our other studies, the PIEB technique produces minimum motor block.

It becomes clear, from our previous and current studies, that other forms of optimization of the PIEB technique will have to be studied if one is interested in producing a less extensive and unnecessary spread of local anesthetics.

One other possible factor to be studied as a potential modifier of the epidural spread is the bolus delivery rate, given that different delivery speeds may generate different pressures in the epidural space. Current PIEB delivery devices may be programmed to deliver PIEB boluses as fast as $500 \mathrm{~mL} \cdot \mathrm{hr}^{-1}$. Most studies published to date have used a bolus delivery rate of $250 \mathrm{~mL} \cdot \mathrm{hr}^{-1}$. Lange et al. ${ }^{26}$ compared two groups of women who received a PIEB bolus either over six minutes $\left(100 \mathrm{~mL} \cdot \mathrm{hr}^{-1}\right)$ or over two minutes $\left(300 \mathrm{~mL} \cdot \mathrm{hr}^{-1}\right)$. The quality of labour analgesia and the need for supplemental analgesia were similar in both groups, suggesting that the speed of injection within the range of $100-300 \mathrm{~mL} \cdot \mathrm{hr}^{-1}$ does not significantly influence the spread of local anesthetic and quality of analgesia. Further studies are warranted to corroborate this finding and look closer into the effects of delivery speed on sensory block levels. 
Our study has some limitations. First, the results of our study may not apply to multiparous women or nulliparous women requesting epidural analgesia in more advanced stages of labour, when dilation of the cervix is greater than $5 \mathrm{~cm}$. We followed women for up to six hours after the epidural placement and did not evaluate the effectiveness of this protocol beyond six hours of labour or during second stage of labour. Second, it is important to highlight that the confirmation of our hypothesis was limited by the study design because of a restricted lower bound in time interval of $30 \mathrm{~min}$. Nevertheless, we had no clinical interest in evaluating intervals smaller than $30 \mathrm{~min}$, given that this would be against our rationale that the studied regimen would consume less local anesthetic. From the data observed in the study, the EI90 likely falls below $30 \mathrm{~min}$ and we used the isotonic regression with extrapolation approach to estimate the EI90, which was $20 \mathrm{~min}$. This interval was outside the interval considered in our hypothesis. The accuracy of the estimate for linear extrapolation is dependent on the shape of the doseresponse curve. Nevertheless, in this study, the true doseresponse curve is unknown and therefore we estimated the accuracy of EI90, the $95 \%$ CI, using bootstrapping simulation method (2000 bootstrap simulations).

In summary, the estimated EI90 for a PIEB regimen with boluses of $2.5 \mathrm{~mL}$ of bupivacaine $0.25 \%$ with fentanyl $8 \mu \mathrm{g} \cdot \mathrm{mL}^{-1}$ using the isotonic regression with extrapolation approach is $20(95 \% \mathrm{CI}, 5.9$ to 28.8$) \mathrm{min}$. Although not meant to be a comparative study, this result suggests that in clinical practice there is no advantage in using this regimen over those using boluses containing the same dose of bupivacaine but in concentrations of $0.0625 \%$ and $0.125 \%$.

Author contributions Daniel Shatalin, Cristian Arzola, Kristi Downey, and Jose C.A. Carvalho contributed to all aspects of this manuscript, including study conception and design; acquisition, analysis, and interpretation of data; and drafting the manuscript. Xiang Y. Ye contributed to study conception and design, analysis and interpretation of data, and drafting the manuscript.

\section{Disclosures None.}

Funding statement Departmental. Dr. Jose Carvalho is supported by the Merit Awards Program from the Department of Anesthesiology and Pain Medicine, University of Toronto.

Editorial responsibility This submission was handled by Dr. Gregory L. Bryson, Former Deputy Editor-in-Chief, Canadian Journal of Anesthesia.

\section{References}

1. Wong CA, Ratliff JT, Sullivan JT, Scavone BM, Toledo P, McCarthy RJ. A randomized comparison of programmed intermittent epidural bolus with continuous epidural infusion for labor analgesia. Anesth Analg 2006; 102: 904-9.

2. Fettes PD, Moore CS, Whiteside JB, McLeod GA, Wildsmith JA. Intermittent vs continuous administration of epidural ropivacaine with fentanyl for analgesia during labour. Br J Anaesth 2006; 97: 359-64.

3. Sia AT, Lim Y, Ocampo C. A comparison of a basal infusion with automated mandatory boluses in parturient-controlled epidural analgesia during labor. Anesth Analg 2007; 104: 673-8.

4. Leo S, Ocampo CE, Lim Y, Sia AT. A randomized comparison of automated intermittent mandatory boluses with a basal infusion in combination with patient-controlled epidural analgesia for labor and delivery. Int J Obstet Anesth 2010; 19: 357-64.

5. Capogna G, Camorcia M, Stirparo S, Farcomeni A. Programmed intermittent epidural bolus versus continuous epidural infusion for labor analgesia: the effects on maternal motor function and labor outcome. A randomized double-blind study in nulliparous women. Anesth Analg 2011; 113: 826-31.

6. Wong CA, McCarthy RJ, Hewlett B. The effect of manipulation of the programmed intermittent bolus time interval and injection volume on total drug use for labor epidural analgesia: a randomized controlled trial. Anesth Analg 2011; 112: 904-11.

7. Сhua SM, Sia AT. Automated intermittent epidural boluses improve analgesia induced by intrathecal fentanyl during labour. Can J Anaesth 2004; 51: 581-5.

8. Lim Y, Sia AT, Ocampo C. Automated regular boluses for epidural analgesia: a comparison with continuous infusion. Int $\mathbf{J}$ Obstet Anesth 2005; 14: 305-9.

9. George RB, Allen TK, Habib AS. Intermittent epidural bolus compared with continuous epidural infusions for labor analgesia: a systematic review and meta-analysis. Anesth Analg 2013; 116: $133-44$.

10. Хи J, Zhou J, Xiao $H$, et al. A systematic review and metaanalysis comparing programmed intermittent bolus and continuous infusion as the background infusion for parturientcontrolled epidural analgesia. Sci Rep 2019; 9:2583. https://doi. org/10.1038/s41598-019-39248-5.

11. Carvalho B, George RB, Cobb B, McKenzie C, Riley ET. Implementation of programmed intermittent epidural bolus for the maintenance of labor analgesia. Anesth Analg 2016; 123: 965-71.

12. Epsztein Kanczuk M, Barrett NM, Arzola C, Downey K, Ye XY, Carvalho JC. Programmed intermittent epidural bolus for labor analgesia during first stage of labor: a biased-coin up-and-down sequential allocation trial to determine the optimum interval time between boluses of a fixed volume of $10 \mathrm{~mL}$ of bupivacaine $0.0625 \%$ with fentanyl $2 \mu \mathrm{g} / \mathrm{mL}$. Anesth Analg 2017; 124: $537-41$.

13. Zakus P, Arzola C, Bittencourt R, Downey $K$, Ye XY, Carvalho $J C$. Determination of the optimal programmed intermittent epidural bolus volume of bupivacaine $0.0625 \%$ with fentanyl 2 $\mu \mathrm{g} . \mathrm{ml}^{-1}$ at a fixed interval of forty minutes: a biased coin up-anddown sequential allocation trial. Anaesthesia 2018; 73: 459-65.

14. Bittencourt $R$, Arzola $C$, Zakus $P$, Downey $K$, Ye XY, Carvalho $J C$. A biased coin up-and-down sequential allocation trial to determine the optimum programmed intermittent epidural bolus time interval between $5 \mathrm{~mL}$ boluses of bupivacaine $0.125 \%$ with fentanyl $2 \mu \mathrm{g} \cdot \mathrm{mL}^{-1}$. Can J Anesth 2019; 66: 1075-81.

15. Hoyle J, Yentis SM. Assessing the height of block for caesarean section over the past three decades: trends from the literature. Anaesthesia 2015; 70: 421-8.

16. Stylianou M, Flournoy $N$. Dose finding using bias the biased coin up-and-down design and isotonic regression. Biometrics 2002; 58: 171-7.

17. Armstrong JS. Forecasting by extrapolation: conclusions from twenty-five years of research. Interfaces 1984; 14: 52-66. 
18. Brezinski C, Redivo Zaglia M. Extrapolation Methods: Theory and Practice. North-Holland; 1991.

19. Pace NL, Stylianou MP. Advances in and limitations of up-anddown methodology: a précis of clinical use, study design, and dose estimation in anesthesia research. Anesthesiology 2007; 107: 144-52.

20. Carvalho B, Riley ET. Programmed intermittent epidural boluses (PIEB) for maintenance of labor analgesia: an incremental step before the next paradigm shift? Turk J Anaesthesiol Reanim 2017; 45: 73-5.

21. Ginosar $Y$, Davidson EM, Firman N, Meroz $Y$, Lemmens $H$, Weiniger $C F$. A randomized controlled trial using patientcontrolled epidural analgesia with $0.25 \%$ versus $0.0625 \%$ bupivacaine in nulliparous labor: effect on analgesia requirement and maternal satisfaction. Int $\mathrm{J}$ Obstet Anesth 2010; 19: 171-8.

22. Sultan P, Murphy C, Halpern S, Carvalho B. The effect of low concentrations versus high concentrations of local anesthetics for labour analgesia on obstetric and anesthetic outcomes: a metaanalysis. Can J Anesth 2013; 60: 840-54.
23. Kaynar AM, Shankar KB. Epidural infusion: continuous or bolus? Anesth Analg 1999; 89:534. https://doi.org/10.1097/00000539199908000-00063.

24. Hogan $Q$. Distribution of solution in the epidural space: examination by cryomicrotome section. Reg Anesth Pain Med 2002; 27: 150-6.

25. Cole J, Hughey S. Bolus epidural infusion improves spread compared with continuous infusion in a cadaveric porcine spine model. Reg Anesth Pain Med 2019. https://doi.org/10.1136/rapm2019-100818.

26. Lange EM, Wong CA, Fitzgerald PC, et al. Effect of epidural infusion bolus delivery rate on the duration of labor analgesia: a randomized clinical trial. Anesthesiology 2018; 128: 745-53.

\section{Publisher's Note}

Springer Nature remains neutral with regard to jurisdictional claims in published maps and institutional affiliations. 